\title{
A SÉTIMA ARTE E A ARTE DE VIVER: O CINEMA E O “ENSINO” DE BIOÉTICA
}

\author{
Pedro Henrique Netto Cezar ${ }^{1}$ Francisco Tavares Guimarães ${ }^{2}$, Heleno Pinto de Moraes ${ }^{3}$, \\ Sávio Silva Santos ${ }^{4}$, Andréia Patrícia Gomes ${ }^{5}$, Rodrigo Siqueira-Batista ${ }^{6}$ \\ ${ }^{1,2}$ Curso de Graduação em Medicina, Centro Universitário Serra dos Órgãos (UNIFESO); Mestrando em \\ Ensino de Ciências, Instituto Federal de Educação, Ciência e Tecnologia do Rio de Janeiro (IFRJ), \\ pedrohnc@uol.com.br \\ frantava@uol.com.br \\ ${ }^{3,4}$ Curso de Graduação em Medicina, UNIFESO, helenopm@gmail.com , saviossy@yahoo.com.br \\ ${ }^{5,6}$ Departamento de Medicina e Enfermagem, Universidade Federal de Viçosa (UFV), \\ andreia.gomes@ufv.br \\ ${ }^{6}$ Programa de Pós-graduação em Bioética, Ética Aplicada e Saúde Pública, \\ Universidade Federal do Rio de Janeiro (UFRJ) rsbatista@ufv.br
}

\section{Resumo}

A relevância da bioética e da arte para a formação do médico, sob um ponto de vista humanista, tem sido tema bastante discutido nos atuais fóruns sobre o ensino da medicina, especialmente no bojo dos currículos baseados nas metodologias ativas de ensino aprendizagem (MAEA). Nestes termos, o uso do cinema desponta como importante recurso pedagógico para a discussão de temas relacionados à bioética, contribuindo assim para que os discentes tenham um espaço para debates e construção de conceitos. Com base nestas considerações, será relatada a experiência vivenciada no Curso de Graduação em Medicina do Centro Universitário Serra dos Órgãos (UNIFESO), com 20 estudantes, no período de setembro a dezembro de 2008, na qual foram trabalhados filmes de cinema - à luz do debate bioético -, utilizando-se os "sete passos" da Aprendizagem Baseada em Problemas (ABP).

Palavras-chave: Ensino médico; Bioética; Metodologias Ativas; Cinema.

\begin{abstract}
The relevance of bioethics and art for the training of a physician, under a humanist point of view, has been greatly discussed in current forums on the teaching of medicine, especially within curricula based on teaching-learning active methodologies (MAEA). In these terms, the use of cinema emerges as an important educational resource for discussing issues related to bioethics, thereby helping learners have a space for debates and the building of concepts. Based on these considerations, it will be reported the experience that took place in the degree course in Medicine at the Centro Universitário Serra dos Órgãos (UNIFESO), with 20 students, in the period from September to December 2008, in which films were worked with - in the light of the bioethical debate - using the "seven steps" of problem-based learning.
\end{abstract}

Keywords: Active Methodologies; Bioethics; Cinema; Medical teaching. 


\section{INTRODUÇÃO}

A bioética tem sido considerada um saber, cada vez mais necessário, para a formação de um médico com as características humanísticas apontadas nas Diretrizes Curriculares Nacionais do Curso de Graduação em Medicina (DCN) (BRASIL, 2001; REGO et al., 2008). De fato, Urban (2003) salienta que essa expansão da bioética se deve, principalmente, ao pluralismo das sociedades contemporâneas, ao grande desenvolvimento da medicina e à medicalização da morte nos hospitais - mormente nas unidades de terapia intensiva (SIQUEIRA-BATISTA \& SCHRAMM, 2005) - dentro de outros aspectos relevantes. Com efeito, deve-se buscar uma interação entre o conhecimento teórico-científico e o humanístico, ultrapassando-se o cientificismo com o qual a medicina vem sendo praticada e ensinada, fortemente baseada no modelo positivista (OUTOMURO, 2008). Este viés cientificista acaba por gerar uma ênfase, precoce, na especialização, o reducionismo biológico e o uso abusivo de tecnologias, os quais seriam traços negativos na prática médica contemporânea, por afastarem o médico do cuidado diário com o paciente, levando à insatisfação das pessoas com relação aos serviços de saúde.

Entre as alternativas que vêm sendo pensadas para ultrapassar estes problemas estão as organizações curriculares baseadas nas metodologias ativas de ensinoaprendizagem (MAEA), as quais se caracterizam por centrarem o processo de construção do conhecimento na figura do estudante, ao contrário do método tradicional (disciplinar), o qual prioriza o papel do professor enquanto transmissor de conteúdos. Como exemplos dessas metodologias, tem-se a Problematização e a Aprendizagem Baseada em Problemas (ABP) (MITRE et al., 2008), as quais valorizam a autonomia do

educando, genuíno autor da própria construção do conhecimento (COSTA \& SIQUEIRA-BATISTA, 2004; FEUERWERKER, 2002). A ABP tem como um dos seus momentos essenciais a sessão tutorial, durante a qual um grupo de estudantes (com oito a dez componentes) trabalha uma situação-problema utilizando o "método" dos sete passos: (1) leitura do problema, identificação e esclarecimento de termos desconhecidos; (2) identificação dos problemas propostos pelo enunciado; (3) formulação de hipóteses explicativas para os problemas, a partir de conhecimentos préexistentes dos estudantes (brainstorm); (4) resumo das hipóteses; (5) formulação dos objetivos de aprendizagem (identificação do que será estudado para aprofundamento do conhecimento); (6) estudo individual dos objetivos estabelecidos; (7) retorno ao grupo 
para rediscussão do problema a partir dos novos conhecimentos adquiridos (VENTURELLI, 2003).

A ABP articula-se muito bem à proposta de um currículo integrado, o qual requer a composição entre teoria e prática - entre as distintas áreas do conhecimento -, em um processo flexível e multidisciplinar - ou, até mesmo inter e transdisciplinar -, levando em conta os saberes, as necessidades individuais de aprendizagem e os problemas da realidade.

Dentro dessas disposições curriculares, o ensino da bioética faz-se extremamente importante, pois engloba temas e situações com as quais o aprendiz certamente irá se deparar em sua vida profissional, muitas das quais demandarão a tomada de decisões que influenciarão na vida do outro (REGO et al., 2009).

Mas afinal, o que e bioética? Rego, Palácios e Schramm (2004) tratam este campo do conhecimento como uma corrente da filosofia moral - uma das éticas aplicadas - que se preocupa em analisar argumentos morais a favor e contra determinadas práticas humanas, que interferem com a qualidade de vida dos seres humanos. Por outro lado, Hottois (2001) define a bioética como sendo um conjunto de pesquisas, de práticas e de discursos pluridisciplinares, que objetivam esclarecer e resolver questões éticas suscitadas pelos avanços e a aplicação das tecnociências biomédicas, abrangendo para isso várias áreas do conhecimento. Mori (1994) ressalta a importância do ensino da bioética na formação médica, na medida em que ao médico é delegada a responsabilidade para cuidar da saúde dos indivíduos e das populações humanas. Com efeito, cabe a este profissional reavaliar constantemente, com senso crítico, seu saberfazer e questioná-lo quanto à repercussão efetiva de seus atos e decisões.

Entre as práticas pedagógicas que permitem a discussão dos temas ligados à bioética, destaca-se o uso de filmes de cinema, os quais permitem criar debates após sua exibição, consubstanciados em torno da apresentação de argumentos sobre a questão em tela (ALVES FERREIRA et al., 2009). Em consonância a tais pressupostos, SiqueiraBatista e colaboradores (2008) defendem a introdução das artes no "ensino" da bioética - especialmente o cinema -, as quais facilitam o processo de ensino-aprendizagem, tornando as aulas menos áridas e ultrapassando a monotonia das atividades muito conteudistas e pouco contextualizadas. Tal recomendação passa pela atual valorização de novas práticas pedagógicas, com a finalidade de potencializar, prazerosamente, o aprendizado do discente. Ademais, a simples apropriação desses recursos por professores ou estudantes, leva à produção de novas perspectivas sobre as questões 
profissionais, uma vez que a arte potencializa o olhar sobre o real (FERREIRA, 2003). A partir desse movimento, é possível desenvolver uma pedagogia crítica que se preocupa com a leitura de imagens.

Os traços humanísticos que os bons profissionais precisam adquirir dizem respeito aos conjuntos de habilidades e competências de natureza variada, os quais englobam os conhecimentos humanísticos (p. ex., o entendimento acerca do respeito à autonomia da pessoa) e a práxis humanística (p. ex., o compromisso em preservar a dignidade dos pacientes) (SIQUEIRA-BATISTA et al., 2009; TAPAJÓS, 2002). Blasco (2002) mostra que é importante permitir que o médico desenvolva recursos para atuar pautado no humanismo, tornando o educando capaz de pensar, refletir e filosofar sobre as próprias atitudes (BLASCO, 2002).

O ensino pelo cinema permite o exercício da reflexão e da emoção por parte do estudante, ao permitir a exploração de situações muito próximas da sua realidade, o que o leva a construir conhecimento, sendo importante, para isso, o debate entre os pares. Dessa forma, o cinema permite a incorporação de diferentes saberes ao cognitivo do indivíduo, sempre baseado na ressignificação que o mesmo faz de seu conhecimento prévio (GOMES et al., 2008). De fato, Marías (1992) considera que o cinema aumenta as possibilidades de vivências, ampliando o repertório de experiências dos sujeitos. Os filmes mostram, muitas vezes, situações bem próximas do cotidiano do espectador, fazendo-o rever posturas e considerar outras hipóteses, ao analisar as situações em tela. Tal aspecto, na medicina, permite ao estudante deixar de lado algumas idéias préconcebidas - eventualmente genuínos preconceitos -, as quais quase sempre atrapalham seu trabalho, especialmente quando neste estão envolvidas questões morais. Marías ainda enfatiza o uso do cinema como um recurso de educação em atitudes humanas, levando em conta, as virtudes e os valores inerentes a cada sujeito.

O cinema, enquanto prática pedagógica inovadora, atua principalmente pelo despertar da emoção do estudante. Ato contínuo torna-se muito mais fácil para o docente chamar atenção para pontos relevantes, muitos dos quais não seriam contemplados em uma discussão formal. Daí a importância do professor que utiliza filmes, "desmontar" seus próprios preconceitos, a fim de conquistar o aluno, para a reflexão.

O objetivo do presente trabalho é relatar a experiência vivenciada no Curso de Graduação em Medicina do Centro Universitário Serra dos Órgãos (UNIFESO), no 
período de setembro de 2008 a dezembro de 2008, utilizando o método dos "sete passos" da ABP para trabalhar filmes de cinema para abordagem temas de bioética.

\section{MÉTODOS}

O planejamento desta investigação se iniciou com a seleção de cinco filmes de cinema capazes de deflagrar debates bioéticos dirigidos às seguintes temáticas: (1) início da vida, (2) pesquisas envolvendo seres humanos, (3) fim da vida, (4) o exercício de poder nas instituições de saúde e (5) o ambiente (REGO et al., 2009). Os filmes escolhidos foram os seguintes:

(1) Regras da vida - Película que enfoca a vida de um médico estadunidense que trabalhava em uma instituição de menores e que, por vezes, realizava abortos, como uma forma de ajudar mulheres que, segundo ele, não poderiam ser auxiliadas de outra forma.

(2) Cobaias - Expõe a história da pesquisa de Tuskegee (o filme é baseado em fatos reais), na qual negros estadunidenses são utilizados como cobaias para investigação da história natural da sífilis.

(3) Mar adentro - Aborda as tentativas de um espanhol tetraplégico, Ramón Sampedro, de conseguir o direito de ser submetido à eutanásia.

(4) Bicho de sete cabeças - Apresenta a história de um jovem usuário de drogas ilícitas (maconha), o qual é colocado por seu pai em uma instituição psiquiátrica, sendo tratado por médicos e enfermeiros como doente mental, sofrendo as conseqüências desta terapia.

(5) Erin Brockovich - Enfoca a história de uma assistente de escritório de advocacia que investiga o adoecimento de diversos indivíduos de uma comunidade localizada próxima a uma indústria que trabalha com mercúrio.

Ato contínuo à seleção dos filmes, 20 estudantes foram convidados para participar da atividade. Todos foram esclarecidos sobre os propósitos da pesquisa e somente após a assinatura do Termo de Consentimento Livre e Esclarecido (TCLE) - tal qual preconizado pela Resolução 196/96 do Conselho Nacional de Saúde, em concordância com a qual o projeto de pesquisa foi analisado e aprovado pelo Comitê de Ética em Pesquisa do Instituto Federal de Educação Ciência e Tecnologia do Rio de Janeiro (IFRJ) (Memorando de aprovação $\mathrm{N}^{0}$ 007/09) -, passou-se à constituição de dois grupos de dez discentes. A súmula das atividades desenvolvidas está apresentada no Quadro 1. 
Durante toda a atividade, o tutor manteve a observação acerca do interesse dos estudantes na discussão, o quanto de conhecimento teórico possuíam das questões bioéticas e principalmente quanto de conhecimento conseguiam construir após as buscas.

Ao término dos cinco filmes, cada aluno deveria preencher um questionário de avaliação, contendo questões fechadas e semi-abertas (Quadro 2), as quais foram posteriormente avaliadas de forma qualitativa, sendo estabelecidas correlações com a literatura.

\section{RESULTADOS E DISCUSSÃO}

Os estudantes de medicina que participaram da atividade possuíam entre 18 e 25 anos - média 18,5 \pm 4,0 ( $\mathrm{X} \pm \mathrm{DP})$-, sendo 13 do sexo feminino e 7 do sexo masculino, provenientes de diferentes períodos. Dez estudantes responderam ao questionário; os demais deixaram de participar, ao longo do processo, por motivo de "falta de tempo" para se dedicar à atividade, segundo afirmado pelos mesmos.

Quadro 1. Planejamento das atividades de discussão bioética, motivadas pelo cinema.

\begin{tabular}{|c|c|}
\hline MOMENTOS & DESCRIÇÃO DA ATIVIDADE \\
\hline $1^{\circ}$ encontro & $\begin{array}{l}\text { - Explicação da natureza e dos objetivos da investigação; esclarecimento } \\
\text { dos sujeitos da pesquisa e assinatura do TCLE; agendamento dos } \\
\text { encontros subsequientes }\end{array}$ \\
\hline $2^{\circ}$ encontro & $\begin{array}{l}\text { - Exposição do filme Regras da vida } \\
\text { - Tutoria* (passos 1, 2, 3, } 4 \text { e 5)** sobre o filme Regras da vida }\end{array}$ \\
\hline $3^{\circ}$ encontro & - Tutoria (passo 7) ${ }^{* * *}$ sobre o filme Regras da vida \\
\hline $4^{\circ}$ encontro & $\begin{array}{l}\text { - Exposição do filme Cobaias } \\
\text { - Tutoria* (passos 1, 2, 3, } 4 \text { e 5)** sobre o filme Cobaias }\end{array}$ \\
\hline $5^{\circ}$ encontro & - Tutoria (passo 7) ${ }^{* * *}$ sobre o filme Cobaias \\
\hline $6^{\circ}$ encontro & $\begin{array}{l}\text { - Exposição do filme Mar adentro } \\
\text { - Tutoria* (passos 1, 2, 3, } 4 \text { e 5)** sobre o filme Mar adentro }\end{array}$ \\
\hline $7^{\circ}$ encontro & - Tutoria (passo 7) ${ }^{* * *}$ sobre o filme Mar adentro \\
\hline $8^{\circ}$ encontro & $\begin{array}{l}\text { - Exposição do filme Bicho de sete cabeças } \\
\text { - Tutoria* (passos 1, 2, 3, } 4 \text { e 5)** sobre o filme Bicho de sete cabeças }\end{array}$ \\
\hline $9^{\circ}$ encontro & - Tutoria (passo 7) ${ }^{* * *}$ sobre o filme Bicho de sete cabeças \\
\hline $10^{\circ}$ encontro & $\begin{array}{l}\text { - Exposição do filme Erin Brokovich } \\
\text { - Tutoria* (passos 1, 2, 3, 4 e 5)** sobre o filme Erin Brokovich }\end{array}$ \\
\hline $11^{\circ}$ encontro & - Tutoria (passo 7) ${ }^{* * *}$ sobre o filme Erin Brokovich \\
\hline $12^{\circ}$ encontro & - Avaliação final da atividade \\
\hline
\end{tabular}

Notas: 
* Logo após a exibição, os mesmos eram conduzidos a uma sala de tutoria, onde o professor, após acomodá-los, distribuía um texto correspondendo ao resumo do filme apresentado - o qual passava a ser processado segundo o procedimentos dos "sete passos" como mencionado anteriormente.

** O primeiro passo do processo tutorial consistia em se ler individualmente a situação e em seguida coletivamente, devendo o tutor indagar sobre termos desconhecidos. A seguir, iniciava-se o processo chamado de brainstorm, onde o tutor tem uma participação importante estimulando os alunos a discutirem a situação, com base em tudo o que viram na tela. Nesta fase é vital que o tutor coordene as atividades do grupo, permitindo que todos tenham sua vez para expor suas idéias e que ouçam uns aos outros. Após 1 hora e meio aproximadamente, os alunos viam os pontos do tema abordado que tiveram dificuldade em discutir, por desconhecimento teórico, elaborando, ato contínuo, hipóteses explicativas, para posterior confirmação ou refutação. Com base nas hipóteses elencadas, os estudantes construíam objetivos de aprendizagem, os quais deveriam ser pesquisados como "estudo individual dos objetivos estabelecidos" (este é o passo 6 da tutoria).

*** Neste passo, sete, cada estudante deveria apresenta os resultados de sua pesquisa, trocando conhecimentos entre si, sendo então fechado o tema.

A atividade foi considerada ótima $(60,0 \%)$ e boa $(40,0 \%)$ pelos discentes (Questão 1). Tal avaliação pode ser explicada a partir do reconhecimento de que práticas educativas fora do modelo tradicional atraem a atenção dos estudantes, ávidos por estratégias de ensino-aprendizagem mais interessantes, que estimulem a reflexão e o poder de crítica. Ademais, ressalte-se que cerca de $80 \%$ do público que freqüenta cinema no Brasil é constituído de jovens universitários (DUARTE, 2006).

Quadro 2. Perguntas do questionário de avaliação aplicado aos estudantes.

\begin{tabular}{|c|l|}
\hline Número & \multicolumn{1}{|c|}{ Questão } \\
\hline 1 & A atividade desenvolvida foi? ( ) Ruim ( ) Regular ( ) Boa ( ) Ótima \\
\hline 2 & $\begin{array}{l}\text { Na sua formação acadêmica você já tinha trabalhado com cinema em sala de aula? } \\
\text { ( ) Sim ( ) Não }\end{array}$ \\
\hline 3 & $\begin{array}{l}\text { Se respondeu Sim na questão anterior, que tipo de atividade foi desenvolvida? } \\
\text { ( ) Discussão de filmes ( ) Vídeos específicos com conteúdos das disciplinas ministradas. } \\
\text { ( ) Outras (especificar): }\end{array}$ \\
\hline 5 & $\begin{array}{l}\text { O que pensa do uso de filmes para discussão de temas ligados à bioética no curso de } \\
\text { medicina? }\end{array}$ \\
\hline 6 & $\begin{array}{l}\text { Você acha que os filmes utilizados conseguiram abordar bem os temas propostos? } \\
\text { ( ) Ruim ( ) Regular ( ) Boa ( ) Ótima }\end{array}$ \\
\hline 7 & $\begin{array}{l}\text { O tutor contribuiu para uma boa discussão dos filmes? ( ) Sim ( ) Não } \\
\text { Qual sua impressão sobre o sistema de avaliação (questionário)? }\end{array}$ \\
\hline 9 & $\begin{array}{l}\text { Você conseguiu construir conhecimento com a atividade realizada? ( ) Sim ( ) Não } \\
\text { Oficácia? }\end{array}$ \\
\hline 10 & ( ) Regular ( ) Boa ( ) Ótima \\
\hline
\end{tabular}

A indagação seguinte diz respeito à experiência com o uso do cinema em práticas pedagógicas (Questão 2 e 3). Do total, 90,0\% nunca haviam trabalhado antes com os filmes de cinema em sala de aula, o que permite conjecturas sobre uma possível predominância de técnicas pedagógicas tradicionais - especialmente no ensino 
fundamental e no médio -, baseadas principalmente na transmissão de conhecimentos e, que, muitas vezes, não apresentam contextualização com a realidade do estudante, levando ao desinteresse pelo aprendizado. Corroborando o exposto, Carmo (2003) enfatiza:

O cinema como prática pedagógica pode fazer o aluno se interessar pelo conhecimento, pela pesquisa, de modo mais vivo e interessante que o ensino tradicional, apoiado em aulas expositivas e seminários. O porquê do cinema na escola só se justifica se ele desperta o interesse pelo ensino no sentido tradicional, e, ao mesmo tempo, mostra novas possibilidades educacionais apoiadas na narrativa cinematográfica.

[CARMO, 2003 p. 72]

O único aluno que respondeu afirmativamente à pergunta relatou experiência prévia com vídeos específicos com conteúdos de disciplinas como Biologia, Física ou Química. Pode ser comentado, a este respeito, que o uso de vídeos educativos é bastante útil como recurso pedagógico, da mesma forma que o filme cinematográfico, concorrendo para a consolidação dos constructos teóricos aprendidos. É uma forma também de estimular o interesse do aluno pela busca e pesquisa. O vídeo educativo já vem sendo utilizado há longa data, possibilitando uma exploração diferente bem como uma melhor visualização dos temas abordados (BOTTENTOUIT, 2009).

Em relação à questão dirigida ao uso de filmes de cinema para discussão de temas ligados à bioética no curso de medicina (Questão 4 e 5), as transcrições a seguir, foram bastante significativas.

- "Achei ótimo. Foi a melhor forma de levantar as questões relevantes e instigar a discussão".

- "Acho bastante interativa e uma forma mais ampla de ver a medicina".

- "Muito interessante a idéia, podendo ser uma atividade fixa no curso".

- "É uma forma menos massante e cansativa e mais prazerosa de estudar esse tema tão importante".

- "Achei interessante a idéia e aprendo muito dessa forma".

- "A importância na formação e amadurecimento de idéias a partir de questões pautadas, vivenciadas no cotidiano, envolvendo a ética médica".

- "É ótimo, pois nos aproximamos do tema a ser discutido, promovendo discussões ricas".

- “Acredito que o cinema facilita a empolgação do aluno para estudar temas relacionados à Bioética, já que não é uma matéria muito discutida no curso de graduação regular".

- "Raro momento de discussão de assuntos de alta pertinência e que acrescentam tanto à nossa formação". 
- "Muito importante para a conscientização do médico acerca da realidade com a qual o mesmo vai se deparar futuramente".

Todos os estudantes que responderam ao questionário $(100,0 \%)$ consideraram que os filmes escolhidos conseguiram abordar bem os temas propostos.

Este é um ponto extremamente importante, pois para chamar a atenção do estudante, a atividade deve ser pautada na aprendizagem significativa, devendo ter correspondência com o tema a ser abordado (GOMES et al., 2008):

Ao escolher um ou outro filme para incluir nas suas atividades escolares, o
professor deve levar em conta o problema da adequação e da abordagem por
meio da reflexão prévia sobre os seus objetivos gerais e específicos. Os fatores
que costumam influir no desenvolvimento e na adequação das atividades são:
possibilidades técnicas e organizativas na exibição de um filme para a classe;
articulação com o currículo e/ou conteúdo discutido, com as habilidades
desejadas e com os conceitos discutidos.

[NAPOLITANO, 2006, p. 16]

A pergunta específica sobre o uso dos filmes como "situação-problema" (Questão 6), a ser trabalhada na ABP (sessão tutorial) mostrou ampla anuência dos estudantes: $40,0 \%$ consideram este método ótimo e 60,0\% bom. O adequado grau de aceitação mostra a necessidade dos estudantes falarem, debaterem suas idéias, aprenderem ouvindo o outro. A troca entre pares é um eficaz método de aprendizagem, por permitir que experiências pessoais sejam relatadas. Isso auxilia na revisão de idéias préconcebidas, permitindo a construção do conhecimento. A sessão tutorial estabelece um espaço para a discussão, com menos alunos, o que evita a dispersão. $\mathrm{O}$ uso de $\mathrm{ABP}$ estimula o educando a se colocar perante seus pares, a utilizar seus conhecimentos prévios acerca do tema discutido e a elaborar hipóteses explicativas e a construção das questões de aprendizado promovendo, assim, o interesse pela pesquisa.

Ainda neste âmbito, 100,0\% dos estudantes destacaram o papel essencial do tutor para uma boa discussão na sessão tutorial (Questão 7). É importante a integração dos tutores com o grupo tutorial e seu conhecimento sobre MAEA, pois sua função é estimular a discussão, trazer os alunos para debate, coordenar os encontros (SIQUEIRA et al., 2009). Além de mediador da atividade, o tutor deve orientar os estudantes durante a confecção das hipóteses e a construção das questões de aprendizagem.

Os discentes se sentiram confortáveis ao preencher o questionário - 50,0\% consideraram o questionário ótimo e 50,0\% bom (Questão 8) -, ponderando sobre o transcorrer da atividade, seus objetivos e execução. 
Do total, $100,0 \%$ consideraram que foi possível construir conhecimento com a atividade realizada (Questão 9). Talvez este seja o aspecto mais importante da avaliação, pois mostra se o objetivo foi alcançado e se esse trabalho pode ser continuado, com número maior de estudantes, até ser plenamente implementado no curso de medicina. Em relação à impressão geral sobre a atividade e às sugestões (Questão 10), os comentários são igualmente apresentados na íntegra:

- "Deveria ter ocorrido uma maior troca de informações entre o grupo. A meu ver, houve momentos em que algumas pessoas não se empenharam. A elaboração de uma síntese com os temas trabalhados seria interessante após cada discussão de filme".

- "Eu acho que foi ótimo da forma que foi feito e acho que foi uma experiência muito enriquecedora, já que de outra forma não teríamos a oportunidade de refletir e discutir temas tão interessantes. Parabéns pela iniciativa".

- "A atividade foi muito proveitosa e as discussões foram excelente".

- "Gostei muito da maneira como o trabalho foi realizado e da dinâmica do grupo".

- "Eu poderia ter me dedicado mais, porém, devido às outras atividades curriculares, não pude fazê-lo".

A avaliação realizada, por questionário, aponta para a caracterização de uma atividade positiva, havendo oportunidade para criação de espaços para debates acerca das questões bioéticas, o que muito contribuiu para a aquisição de conhecimentos entre pares. Porém, o trabalho em grupo requer um cuidado do professor no sentido de socializar seus integrantes, a fim de criar um ambiente harmônico e produtivo para todos. Um dos entraves à pesquisa foi a preocupação com os outros conteúdos curriculares do curso, o que afastou metade dos interessados. Se a atividade fosse incluída no programa curricular provavelmente isso não aconteceria.

\section{CONSIDERAÇÕES FINAIS}

A presente comunicação apresenta dados sobre o uso do cinema para o ensino de bioética no contexto das MAEA. Empregou-se, de modo vanguardista, o processo tutorial utilizado na $\mathrm{ABP}$, trabalhando-se cinco filmes de cinema como situaçõesproblema. Grande parte dos alunos nunca tinha utilizado recursos audiovisuais em sala de aula, porém, reconheceram a relevância do emprego do cinema, para aproximá-los das questões biopsicossociais inerentes à qualidade de vida das pessoas. $O$ desenvolvimento das humanidades médicas através do cinema, por ser uma atividade 
lúdica e prazerosa, chama a atenção dos discentes. Além disso, a adoção de uma MAEA - na qual o estudante pode debater com seus pares, trocar informações e retirar objetivos de aprendizagem para aprofundamento e construção do conhecimento -, foi vital para os resultados obtidos.

Em relação ao professor, ressalta-se que o mesmo deve atuar no sentido de estimular a discussão, trazer para o debate fatos levantados nos filmes, sempre respeitando os conceitos que cada um traz em sua bagagem cultural, mas convidando à reflexão de novas possibilidades de pensamento. Dessa maneira, o aprendiz lança um olhar ampliado para o paciente, com agregação de novos saberes, não calcado apenas no conhecimento técnico.

A atividade realizada na atual pesquisa mostrou que, se bem trabalhada, pode ser incluída no plano curricular do curso de graduação em medicina. Isso demanda que os responsáveis tenham um conhecimento amplo da filosofia das MAEA e de sua execução e que, ao escolherem os filmes, tenham o cuidado de relacioná-los aos temas que vão ser abordados, para que o aprendizado seja complementar e genuinamente significativo.

\section{REFERÊNCIAS}

ALVES-FERREIRA, R.; ANDRADE, T. S.; RÔÇAS, G.; HELAYËL-NETO, J. A.; SIQUEIRA-BATISTA, R. Cinema e ensino de física. Anais do XVIII Simpósio Nacional de Ensino de Física. São Paulo: Sociedade Brasileira de Física, v. 1. p. 1-8, 2009.

BLASCO, P. G. Medicina da família \& cinema: recursos humanísticos na educação médica. São Paulo: Casa do Psicólogo, 2002.

BOTTENTOUIT, J. J. B.; COUTINHO, C. P. Desenvolvimento de vídeos educativos com o Windows Movie Maker e o Youtube: uma experiência no ensino superior. VIII LUSOCOM: comunicação, espaço global e lusofonia. Lisboa: Universidade Lusófona de Humanidades e Tecnologia, p. 1052-1070, 2009.

BRASIL. Congresso. Senado. Resolução n. 4 CNE/CES, de 2001. Institui Diretrizes Curriculares Nacionais do Curso de Graduação em Medicina. Diário Oficial da União. Brasília, Seção 1, p. 38, 9 de novembro de 2001.

CARMO, L. O cinema do feitiço contra o feiticeiro. Revista Iberoamericana de Educación, n. 32, p.71-94, 2003.

COSTA, C. R. B. S. F.; SIQUEIRA-BATISTA, R. As teorias do desenvolvimento moral e o ensino médico: uma reflexão pedagógica centrada na autonomia do educando.

Revista Brasileira de Educação Médica, v. 28, n. 3, p. 242-250, 2004.

DUARTE, R. Cinema e educação. Belo Horizonte: Autêntica, 2006 
FERREIRA, L. W. Educação e mídia: O visível, o ilusório, a imagem. Porto Alegre: EDIPUCRS, 2003.

FEUERWERKER, L. Além do discurso de mudança na educação médica: processos e resultados. São Paulo: HUCITEC, 2002.

GOMES A. P.; DIAS-COELHO, U. C.; CAVALHEIRO, P. O.; GONÇALVESA, C. A. N.; RÔÇAS, G.; SIQUEIRA-BATISTA, R. A Educação médica entre mapas e âncoras: a aprendizagem significativa de David Ausubel, em busca da arca perdida. Revista Brasileira de Educação Médica, v. 32, n. 1, p.105-111, 2008.

HOTTOIS, G. Nouvelle encyclopédie de bioéthique. Bruxelles: De Boeck, 2001.

MARÍAS, J. La educación sentimental. Madrid: Alianza Editorial, 1992.

MITRE, S. M.; SIQUEIRA-BATISTA, R.; GIRARDI-DE-MENDONÇA, J. M.; MORAIS-PINTO, N. M., et al. Metodologias ativas de ensino-aprendizagem na formação profissional em saúde: debates atuais.Ciência e Saúde Coletiva, v.13, p.2133-2144, 2008.

MORI, M. A bioética: sua natureza e história. Humanidades, v.9, n. 4, p. 332-341, 1994.

NAPOLITANO, M. Como usar o cinema na sala de aula. São Paulo: Contexto, 2006.

OUTUMURO, D. Fundamentación de la enseñanza de la bioética en medicina. Acta Bioethica v. 14 n. 1, p. 1-10, 2008.

REGO, S; PALACIOS, M.; SCHRANN, F R. Ensino da bioética nos cursos de graduação em saúde. In: MARINS, J. J. N.; REGO, S.; LAMPERT, J. B. ARAÚJO, J. G. C. Educação Médica em Transformação: Instrumentos para a Construção de Novas Realidades. São Paulo/ HUCITEC, 2004.

REGO, S.; GOMES, A. P.; SIQUEIRA-BATISTA, R. Bioética e humanização como temas transversais na formação médica. Revista Brasileira de Educação Médica, v.32, n.4, p. 482-491, 2008.

REGO, S.; PALÁCIOS, M.; SIQUEIRA-BATISTA, Bioética para profissionais da saúde. Rio de Janeiro: Editora FIOCRUZ, 2009.

SIQUEIRA, J. R. M.; SIQUEIRA-BATISTA R.; MORCH, M. B.; SIQUEIRABATISTA, R.. Aprendizagem Baseada em Problemas: o que os médicos podem ensinar para os contadores. Contabilidade Vista \& Revista, v. 20, p. 101-125, 2009.

SIQUEIRA-BATISTA, R.; SCHRAMM, F. R. conversações sobre a boa morte: o debate biomédico acerca da eutanásia. Cadernos de Saúde Pública, v. 21, n.1, p.111$119,2005$.

SIQUEIRA-BATISTA, R.; GOMES, A P; RÔÇAS, G.; LEITE, S Q M; SIQUEIRABATISTA, R. Uso do cinema na formação bioética de professores de ciências. In: Encontro nacional de ensino de ciências da saúde e do ambiente, 2008, Niterói. Anais do encontro nacional de ensino de ciências da saúde e do ambiente. Niterói: MPE/ UNIPLI, p. 309-317, 2008. 
SIQUEIRA-BATISTA, R.; GOMES, A P; ARCURI, M. B. Bioética e cinema: a arte e a ética em movimento na formação docente. Revista Brasileira de Educação Médica, v. 33. p. 197-197, 2009.

TAPAJÓS, R. A Introdução das artes nos currículos médicos. Interface Comunicação, Saúde, Educação, v. 6, n. 10, p. 27-36, 2002.

URBAN, C. A. Bioética e a prática médica. Jornal Vascular Brasileiro, v. 2, n. 3, p. 275-277, 2003.

VENTURELLI, J. Educación médica: nuevos enfoques, metas y métodos. $2^{\mathrm{a}}$ ed. Organización Panamericana de La Salud, 2003. 